\title{
Uma novidade bombástica: Imagens publicitárias de automóveis em um periódico curitibano de 1913
}

\author{
Naiara Batista Krachenski ${ }^{1}$
}

Resumo: Pretendemos entender neste trabalho como o discurso da modernidade que chegava ao Brasil e a Curitiba no início do século $\mathrm{XX}$ se fazia presente nas representações imagéticas cotidianas e o modo pelo qual a publicidade participava na construção destas mensagens através dos recursos visuais. Para tanto, são analisadas propagandas dos automóveis BENZ presentes na revista $A$ Bomba (1913) utilizando uma metodologia de análise que consiste em considerar a linguagem própria da imagem e interpretar alguns de seus possíveis significados históricos.

Palavras-Chave: Automóveis, Artes Visuais, Modernidade, Publicidade.

\section{História e Artes Visuais: algumas considerações metodológicas}

Com a incorporação de novos tipos de fontes históricas e de novas problemáticas abordadas pelos estudiosos a partir da Escola dos Annales, iniciaram-se indagações a respeito de como trabalhar com novos objetos. Contudo, somente a partir de meados dos anos 1980 os historiadores vêm debatendo acerca da utilização das fontes visuais. Se textos escritos possuem uma linguagem própria de acordo

\footnotetext{
${ }^{1}$ Em setembro de 2010, aluna do sexto período de graduação em História da UFPR. Este trabalho é orientado pela Professora Doutora Rosane Kaminski.
}

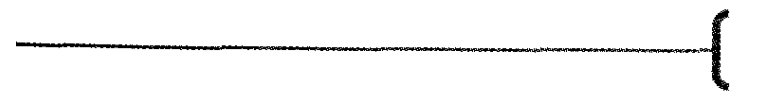


com o período em que foram produzidos e todas as outras implicações para a historiografia, porque ao trabalhar com imagens estas questões não eram abordadas pelos historiadores? Perguntas como esta passaram a chamar a atenção dos pesquisadores e logo os trabalhos historiográficos passaram a incorporar os conhecimentos produzidos pelas áreas das Artes Visuais e da Semiótica, por exemplo.

A principal contribuição da Semiótica para a História foi compreender a linguagem específica pela qual a imagem expressa seus significados, bem como o modo pelo qual conteúdo e forma estão intimamente ligados neste processo. Também a noção de processo foi incorporada nesses estudos, ou seja, a representação seja ela qual for - não é mais entendida como o resultado de uma apropriação pura da realidade, mas é percebida enquanto um processo de construção do real ${ }^{2}$. Questões acerca da natureza e das especificidades da imagem são de fundamental importância para nosso estudo, contudo, neste trabalho procuraremos enfocar mais as questões metodológicas do trabalho com as fontes visuais ${ }^{3}$.

\footnotetext{
${ }^{2}$ A questão da semelhança entre a imagem e a realidade e seus debates mais específicos são apresentados por Jacques Aumont em seu trabalho intitulado $A$ imagem. (Aumont, 1993: 197-254)

3 Sobre questões teóricas iniciais acerca das especificidades da imagem ver Aumont, 1993; Joly, 1996 e Sorlin, 1994.
} 
Feitas as reflexões necessárias para sustentar o valor da imagem como fonte legítima para o trabalho histórico, fica a pergunta: então, como fazer? Sobre esta indagação vários autores têm apresentado apontamentos metodológicos e, dentre estes, consideramos que o trabalho de Artur Freitas clareia nosso caminho. No artigo História e imagem artística: por uma abordagem triplice o autor propõe que se leve em consideração pelo menos três dimensões ao estudar fontes imagéticas: a dimensão formal, que analisa a lógica própria da composição visual; a dimensão semântica, que considera os conteúdos da imagem e a dimensão social, que entende a imagem como um signo cultural determinado (Freitas, 2004: 3-4). É a partir desta delimitação metodológica que encaminharemos nossas análises, uma vez que ela leva em conta questões pertinentes à linguagem própria das imagens e vai além, pois busca compreender sua historicidade e seu contexto de produção e circulação.

\section{A Modernidade em Curitiba}

Neste artigo trabalhamos com propagandas de automóveis encontradas na revista curitibana $A B O m b a^{4}$ que circulou na cidade

\footnotetext{
4 A historiadora Rosane Kaminski, ao fazer um levantamento das revistas curitibanas de 1900 a 1920, definiu pelo menos três classificações para elas: a) revistas literárias; b) revistas de humor e c) revistas de caráter publicitário ou de promoção institucional. A revista $A B o m b a$ se enquadra na segunda opção, por ser uma revista que veiculava muitas charges e por que suas manchetes possuíam um
} 
de junho a dezembro de 1913. Este ano faz parte de um momento de grandes mudanças pelo qual passava não só a pequena cidade de Curitiba, mas também várias capitais brasileiras. De acordo com Nicolau Sevcenko, houve na virada do século XIX para o século XX uma brusca mudança nos cenários e nos comportamentos urbanos nas grandes cidades do mundo, como Paris e Londres. Com o advento de novas tecnologias e com os deslocamentos populacionais mais intensos, as cidades se transformaram nas vitrines das novas técnicas e postulavam a chegada de um novo tempo, a modernidade. As transformações que ocorriam em âmbito mundial também podiam ser vistas no Brasil, uma vez que o país estava inserido na lógica da economia capitalista internacional e se pretendia 'antenado' às novas concepções de mundo que vinham da Europa. Nesse momento, as revistas ilustradas que circulavam com uma freqüência cada vez maior auxiliavam na construção de um ideário moderno, pois, segundo a historiadora Rosane Kaminski, além de elas reforçarem

caráter "bem-humorado". Além disso, A Bomba foi uma das revistas dessa época que mais deu ênfase à imagem. Seu título já possuía um aspecto bem típico do art nouveau, com letras bem desenhadas e sinuosas e em seu interior encontramos várias charges e caricaturas. Contudo, apesar desta profusão de imagens, Kaminski aponta para o fato de que não havia uma coerência estilística em seus desenhos. Ao que parecem, os editores testavam a cada número um design diferenciado. Sobre este fenômeno, a historiadora afirma que ele se dava pela incipiência de um meio artístico em Curitiba naquela época. Por isso, portanto, a falta de profissionais dessa área gerava uma menor qualidade das imagens das revistas curitibanas quando comparadas às revistas da mesma época do Rio de Janeiro e de São Paulo, por exemplo. Ver Kaminski, 2010b. 
padrões de gosto e comportamentos que se viam nas grandes metrópoles, elas também criavam novas percepções de mundo a partir dos esquemas gráficos e das inovações técnicas que apresentavam.

Aqui é importante lembrar, conforme aponta Renato Ortiz (1988: 31-37), que no Brasil "a idéia de moderno se associa a valores como progresso e civilização". Tal ideia sobre a modernidade devese ao fato de há uma associação freqüente de que uma sociedade moderna é uma sociedade racional. A partir dessa afirmação, estabelece-se o paradigma de que a razão determina a ação humana em seu agir no mundo e, conseqüentemente, o triunfo da razão e da ordem científica. Sob esta perspectiva, ciência e técnica seriam os instrumentos por excelência da modernização (TOURRAINE, 1994: $17-20)^{5}$.

Porém, apesar de a mensagem publicitária aqui analisada considerar a modernidade como algo positivo, a partir de um dos símbolos do progresso e da civilização, não podemos nos enganar e pensar que esta era a única ideia acerca da modernidade e suas

${ }^{5}$ É importante destacarmos aqui que na primeira parte do livro (Parte 1: O triunfo da Razão), Tourraine explora outras definições do conceito de modernidade. A ligação entre sociedade moderna e sociedade racional é apenas uma delas, e este conceito não se reduz a ela. Além disso, devemos considerar a separação entre esfera pública e esfera privada, a substituição de Deus pela Ciência no centro das explicações e a clivagem que ocorre nesse processo entre Sujeito e Objeto (TOURRAINE, 1994: 15-95) 
transformações que circulavam no Brasil e, mais especificamente, em Curitiba. As charges veiculadas pela mesma revista $A$ Bomba nos permitem interpretar a recepção dessas transformações sob um outro olhar, um olhar mais crítico, olhar daqueles que estão "fora" do projeto modernizador brasileiro.

\section{A Publicidade de automóveis BENZ em $\boldsymbol{A}$ Bomba}

A partir deste conceito de modernidade que se queria solidificar no Brasil, a publicidade de automóveis presente n' $A$ Bomba tinha pelo menos duas funções primordiais: apresentar este objeto à população curitibana, relacionando-o com o progresso científico e tecnológico e reforçar os esquemas imagéticos pelo qual a modernidade deveria ser entendida.

De fato, a principal função da publicidade é criar necessidades sociais através das significações que constrói. Para Baudrillard, inclusive, esta função é anterior e mais importante que a função de persuasão por uma ou outra marca (Baudrillard, 1969: 271-272). Nesse sentido, a publicidade é um dos veículos pelos quais se edificam os símbolos ${ }^{6}$ de uma sociedade. Ela dá coerência a uma

\footnotetext{
${ }^{6}$ Charles Peirce distingue três tipos de funções dos signos visuais: o ícone, o índice e o símbolo. O ícone trava uma relação de analogia com o objeto que representa, ou seja, estabelece-se uma relação de similitude. O índice mantém uma relação de contigüidade com o objeto representado e se relaciona com ele devido a ligações físicas entre o objeto e a representação. Os simbolos, por sua vez, são signos que
}

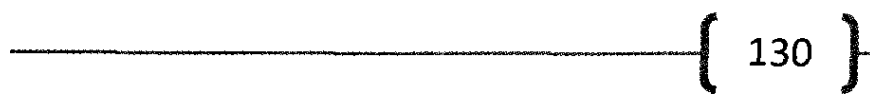


série de valores de determinada coletividade através de um discurso de igualdade entre os consumidores. No entanto, como notou Baudrillard, essa igualdade é um mito, pois, na prática, o que existe é um processo de significação para a diferenciação social. A produção de significantes é feita para se manter uma lógica e uma unidade social baseadas nos desejos individuais. Tal ordem é transmitida pela publicidade de uma maneira indireta através de um jogo entre ter e não ter, através da gratificação do olhar e da frustração pela ausência do que se deseja (Baudrillard, 1969: 276). É dessa forma que a diferenciação social se realiza, a partir de uma confrontação entre o indivíduo e a sociedade, uma vez que a aquisição de determinado objeto só tem valor dentro de um grupo que lhe assegura determinado valor. Mais uma vez, o valor do objeto não está nele mesmo, mas nos significados sociais que lhe são atribuídos dentro de determinada formação cultural.

A partir desses processos de construção dos significados pela publicidade, a historiadora Márcia Padilha afirmou que nessa mesma lógica as propagandas também constroem as subjetividades urbanas. Estas são afirmadas no espaço público ${ }^{7}$ e permitem que os indivíduos compartilhem desejos e percepções acerca do mundo.

mantém uma relação de convenção com o referente. Tal convenção é construída sócio-culturalmente. Ver Joly, 1996.

${ }^{7}$ Sobre a questão da transferência da formação de subjetividades do espaço privado para o espaço público na cultura midiática ver Habermas, 2003.

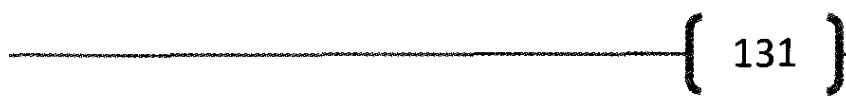


Certamente, nessa linha de pensamento, devemos considerar que a apreensão dos significados produzidos (ou reforçados, no caso das nossas propagandas) depende das condições específicas de seus leitores ${ }^{8}$.

Como dito anteriormente, as propagandas dos automóveis BENZ que circulavam n'A Bomba veiculavam certas percepções da sociedade moderna que se queria para a pequena Curitiba do início do século XX. Os signos desta sociedade, contudo, não eram construídos unicamente pelos objetos anunciados, mas também pela forma como eram apresentados aos leitores.

A primeira propaganda BENZ [imagem 01] circulou na revista número 7 no mês de agosto, portanto já no terceiro mês que $A$ Bomba vinha a público. Nela o automóvel é representado por um desenho bem técnico ${ }^{9}$, de linhas retas e em preto e branco. O carro está em destaque na posição central da propaganda sobre um fundo laranja de cor chapada, o que lhe confere a preeminência do olhar do

${ }^{8}$ Roger Chartier afirma em seu texto clássico O mundo como representação (1991) que a leitura depende das condições históricas e sociais nas quais os indivíduos estão inseridos, bem como não há uma única forma de compreensão e utilização dos textos, mas múltiplas significações que os sujeitos atribuem.

9 Utilizamos esta expressão "desenho técnico" para nos referir a um desenho caracterizado pela sua normatização e pela apropriação que faz das regras da geometria descritiva. $O$ desenho técnico é um dos principais elementos de um projeto arquitetônico ou de engenharia, por exemplo. (http:// pt.wikipedia.org/ wiki/Desenho_técnico - acesso em 23/02/2011). Nas nossas análises, esta expressão está em oposição ao que denominamos "desenho artístico", cujos traços são menos precisos e mais livres. 
espectador. A marca, o slogan e as informações sobre o representante no Paraná se repetem ao longo das propagandas aqui analisadas. Podemos perceber que neste anúncio a imagem do automóvel possui um caráter demonstrativo como um meio de transporte novo, uma vez que o primeiro a circular em Curitiba foi trazido em 1903 por Francisco Fido Fontana - o mesmo personagem a quem a propaganda faz referência e que era um grande empresário do ramo da erva-mate no Paraná, ou seja, possuía na época fortuna e destaque social ${ }^{10}-\mathrm{e}$ um caráter representativo de uma ordem social também nova, a ordem da técnica e da ciência. Como foi mencionado anteriormente, a partir das considerações de Renato Ortiz, a noção de moderno entrava no Brasil associada ao ideário liberal e aos valores de progresso e civilização que chegavam principalmente da Europa. Já o texto do anúncio tem um caráter informativo no sentido de associar o "automóvel preferido" à marca BENZ e a indicar quem é o representante da marca no Paraná.

\footnotetext{
${ }^{10}$ O automóvel trazido em 1903 era um Renault modelo La Minerve. Além da sua posição social enquanto empresário do ramo ervateiro, importante ciclo econômico paranaense no final do século XIX e início do século XX, até 1912, quando do falecimento de sua primeira esposa, Fido Fontana era genro do Barão do Serro Azul, importante figura no cenário da elite paranaense.
} 


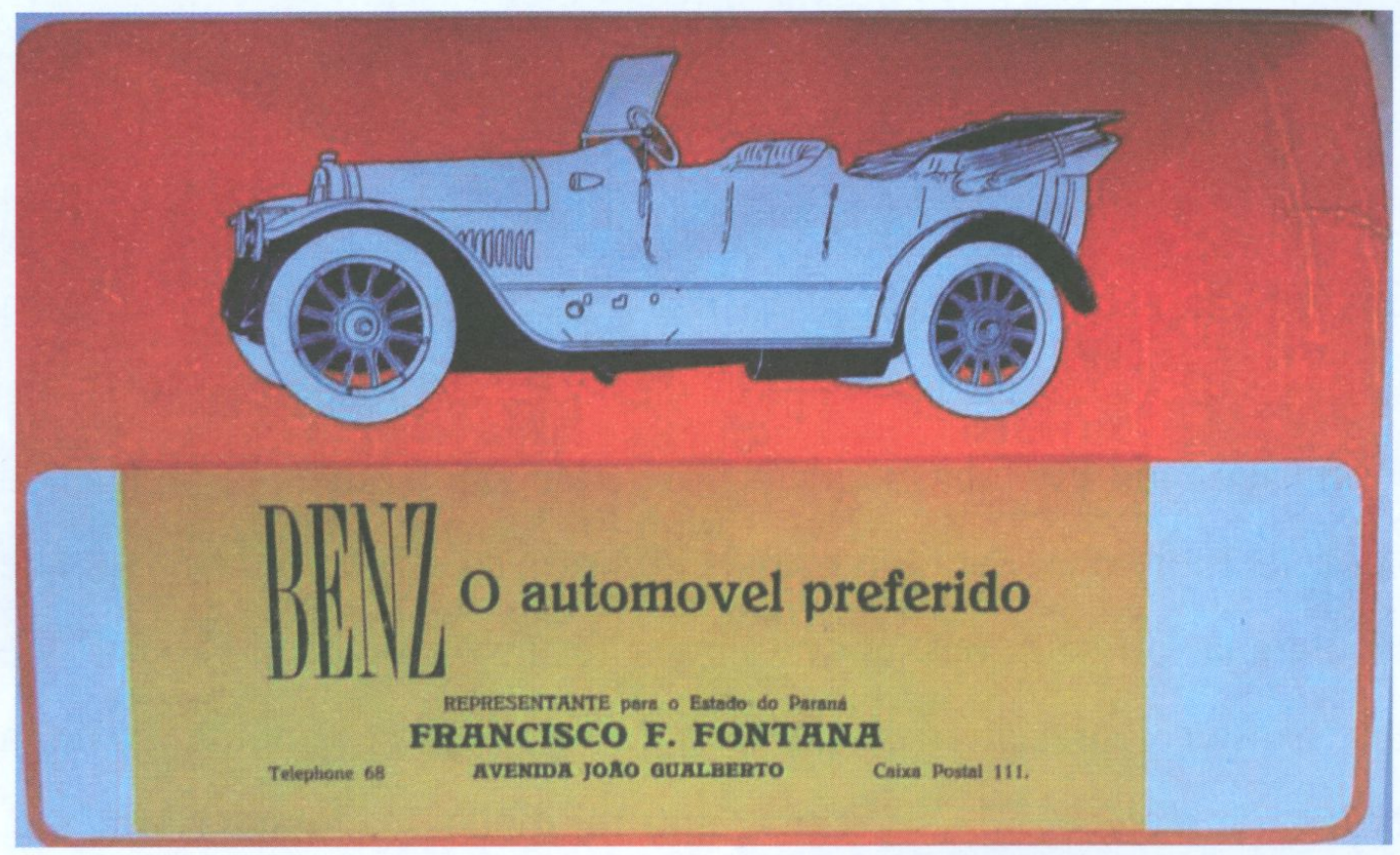

\section{Imagem 1: Quarta capa anúncio automóveis Benz}

\section{A Bomba n07 ago/1913}

Como apontou Artur Freitas no artigo mencionado anteriormente, ao trabalharmos com fontes visuais devemos fazer um primeiro procedimento de análise que ele denomina de isolamento metodológico, ou seja, destacar o objeto a ser estudado e entender suas estruturas formais para depois "devolvê-lo" no todo e compreendê-lo enquanto um produto social através de suas significações. Nas nossas análises, ao isolarmos temporariamente as representações do automóvel nas publicidades, podemos entender que tal representação apresenta variadas formas ao longo dos 
anúncios BENZ na revista $A$ Bomba. Nesta primeira propaganda, a diagramação do anúncio é feita de forma tal que o percurso do olhar é inicialmente atraído pela representação técnica do automóvel. Segundo Joly, esta é uma construção denominada de axial, quando o produto é colocado no eixo do olhar, no centro do anúncio. É uma diagramação que destaca o objeto da propaganda e é utilizada quando um produto é novo no mercado (JOLY, 1996: 98).

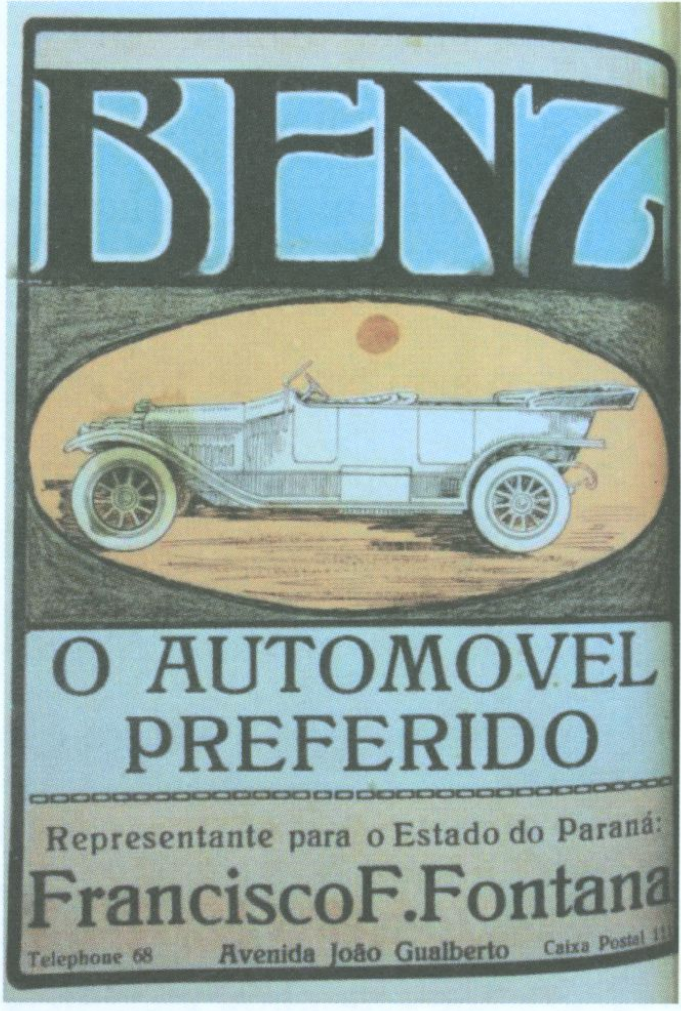

Imagem 2: Quarta capa anúncio automóveis Benz $A$ Bomba n$^{0} 10$ set $/ 1913$

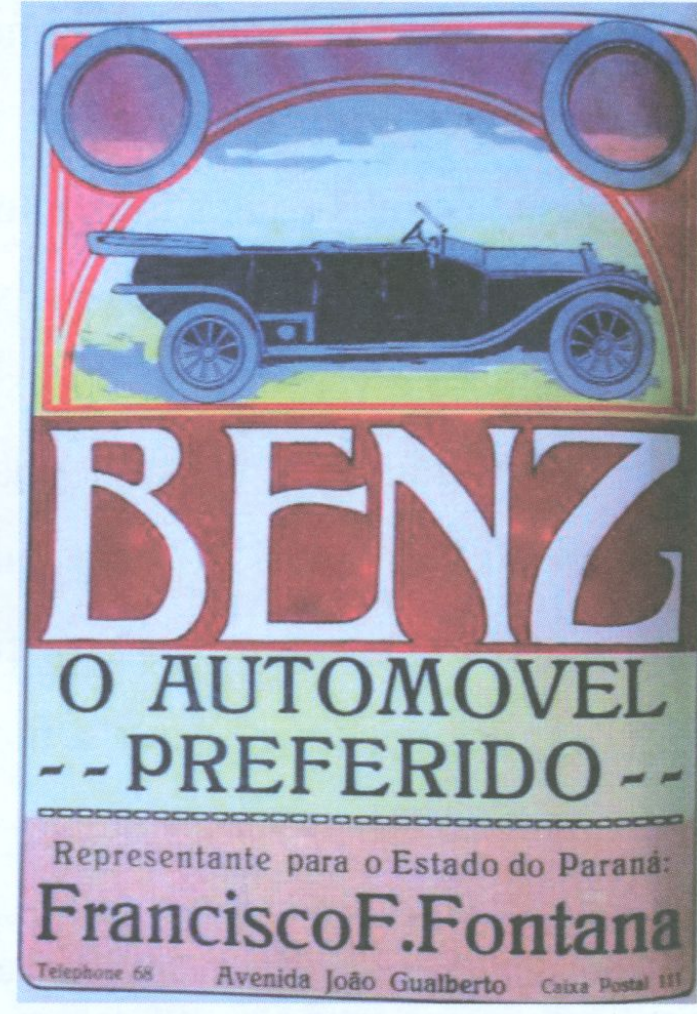

Imagem 3: Quarta capa anúncio automóveis Benz A Bomba n'15 out/1913 
Já as imagens 2 e 3 são propagandas de setembro e outubro. Como podemos ver, sua composição é diferente da anterior. Elas podem ser divididas em três partes: uma parte da representação do automóvel, outra com o nome da marca e outra com a caixa de texto que contém as informações sobre o representante e o slogan. $\mathrm{Na}$ parte superior da imagem 2 se encontra o nome da marca em um destaque maior que na imagem 1. As letras de BENZ são grandes e desenhadas em estilo art nouveau ${ }^{11}$, muito utilizado nos periódicos da época, e está sobre um fundo azul claro. Ainda aqui a representação do automóvel é um desenho técnico, porém as hachuras e as linhas que simulam o chão lhe conferem mais volume e uma espacialidade um pouco mais definida. As cores deste anúncio são gelo, ocre e verde escuro. Dessa forma, o azul claro ao fundo da marca lhe garante um destaque maior. A propaganda 3, por sua vez, mantém uma composição bem parecida com a anterior. Contudo, a representação do automóvel é distinta, pois ele está pintado de preto com detalhes em cinza. Aqui, a moldura que circunscreve o carro e o

${ }^{11} \mathrm{O}$ art nouveau se desenvolveu na Europa no final do século XIX e era um estilo decorativo presente na arquitetura e nas artes gráficas. Uma de suas propostas era o fim das distinções entre a "Grande Arte" e as "artes aplicadas" que se apresentava na união da Arte e da indústria. As principais características visuais desse estilo são as linhas sinuosas e formas arredondadas e assimétricas. $O$ colorido também faz parte do seu poder de sedução, uma vez que era um estilo muito ligado ao consumo. Para mais informações sobre o art nouveau ver Raimes, 2007 e Cardoso, 2008 . 
Cadernos de Clio, Curitiba, n. ${ }^{\circ} 2,2011$

desenho da marca estão em sintonia, na medida em que o fundo vermelho de BENZ se liga de uma maneira muito sutil à representação do automóvel, ou seja, eles se conjugam para darem uma impressão de ligação extrema entre o automóvel e a marca anunciada.

Em $A$ cidade como espetáculo, Márcia Padilha apresenta pelo menos quatro sentidos pelos quais a publicidade definia o termo moderno. O primeiro era entender a modernidade como uma representação do progresso científico, linear e cumulativo; a segunda era relacionar o moderno aos maquinismos $\mathrm{e}$ às tecnologias responsáveis pelas novas percepções sensoriais; a terceira era a que associava o termo moderno a um estilo de vida cosmopolita baseado no consumo de bens de luxo e nos hábitos comportamentais europeus e estadunidenses e finalmente, entendiam a modernidade como o ideal da ordem social burguesa (Padilha, 2001: 105). Nestas três propagandas verificamos que a modernidade se ligava à tecnologia e ao progresso cientifico, pelas representações técnicas dos automóveis. Contudo, a composição das imagens sugere o apelo ao maior poder de sedução que as novas técnicas de impressão e confecção das propagandas possibilitaram. De forma indireta, a qualidade das imagens representa este novo ideal burguês de luxo e de consumo requintado. Dessa forma, esses conceitos iam se 
destilando entre os leitores que passavam a adotar novos hábitos comportamentais $^{12}$.

Entretanto, se podemos dizer que estas primeiras propagandas que circulavam na revista $A$ Bomba já deveriam impressionar seus leitores, as propagandas que analisamos a partir de agora têm um destaque maior às técnicas de confecção das ilustrações da publicidade. Como podemos ver na imagem 4, presente na revista de novembro, a propaganda está dividida em duas partes e não em três, como as anteriores. Aqui a marca e a representação do automóvel fazem parte da mesma composição visual. Diferentemente das propagandas anteriores, vemos um carro vermelho, verde e branco que é representado dentro de uma cena, em um desenho mais artístico e menos técnico que os precedentes. A maior diferença desta propaganda com relação às demais é que temos a impressão de que o automóvel está em movimento, o que fica evidente pela echarpe que voa envolta ao pescoço da moça. Além disso, o fato de haver nesta representação duas pessoas - o motorista

\footnotetext{
${ }^{12}$ Este processo de incorporação dos novos hábitos de uma sociedade moderna não era feito, evidentemente, exclusivamente pelas propagandas de automóveis. A revista $A$ Bomba apresentava uma variedade de anúncios sobre os mais diversos produtos. Os que mais se repetem ao longo de seus números são aqueles que procuram vender novos cosméticos, roupas e sapatos. Em todos eles, as imagens não são tão representativas quanto nas propagandas BENZ, porém a linguagem utilizada sempre remete ao novo, ao milagroso e à moda internacional, elementos próprios de uma cultura cosmopolita, dita moderna.
} 
e a mulher - já é indicativo de uma certa mudança nos padrões de representação do automóvel. Até aqui ele era apresentado aos espectadores um objeto de contemplação, símbolo da ciência e do progresso da modernidade. Daqui pra frente as imagens nos mostram que além disso ele é o objeto preferido de desfrute do luxo e de lazer dos novos tempos. O cenário no qual o carro está inserido parece ser uma paisagem campestre, devido às montanhas ao fundo ${ }^{13}$. De acordo com Joly, esta é uma representação em profundidade, uma vez que o produto do anúncio - no caso o automóvel - é integrado em uma cena em perspectiva e está à frente dela, em primeiro plano (Joly, 1996: 98).

\footnotetext{
${ }^{13}$ É bom lembrarmos que o campo aqui se remete ao campo do lazer, do descanso daqueles que trabalham no meio urbano e têm a possibilidade de escapar de suas realidades tumultuadas. Esta perspectiva está em oposição ao campo do trabalhador, onde a terra é seu sustento de vida e, por vezes, a causa de suas dificuldades.
} 


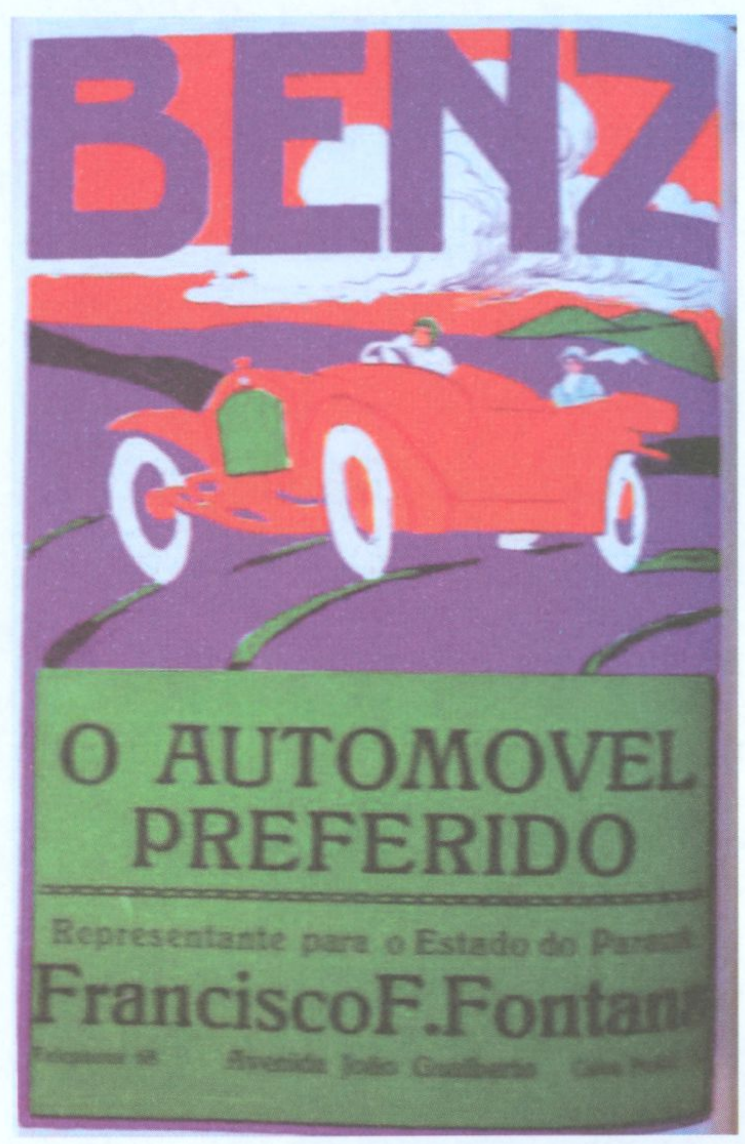

Imagem 4: Quarta capa anúncio nov/1913 automóveis Benz $A$ Bomba $\mathbf{n}^{0} 16$

É interessante notarmos as cores deste anúncio. $\mathrm{O}$ céu vermelho, as montanhas verdes e a terra em um roxo vibrante denunciam que não havia uma pretensão de analogia com a realidade. Pelo contrário. A brincadeira feita com as cores combina com a noção de movimento do desenho e confere à imagem um tom divertido e até lúdico, representativo dos ideais burgueses modernos. Além do mais, uma das funções práticas da

publicidade é criar o desejo nos consumidores e inseri-los em uma nova lógica social. A criação de uma espacialidade concreta nas 
representações dos automóveis garante uma aproximação maior com aqueles que liam $A B o m b a^{14}$.

A imagem 5 também possui esse caráter apelativo aos sentimentos modernos. Enquanto a propaganda acima possui um tom lúdico, esta possui um aspecto mais sensual, devido ao estilo das letras de BENZ e da própria representação do automóvel que possui três pessoas, um homem e duas mulheres. A composição da imagem é novamente dividida em três partes. Na primeira, vemos um carro em vermelho com três pessoas que parecem estar desfrutando de um momento divertido proporcionado não só pela companhia de amigos, mas, principalmente, pela presença do automóvel. Esta imagem é circundada por uma moldura vermelho e laranja em um estilo bem típico do art nouveau, com suas formas orgânicas e arredondadas, o que confere também fluidez e tem um quê de feminilidade que combina com a representação das duas mulheres na cena. $\mathrm{Na}$ segunda parte da imagem estão as letras que compõe a palavra da marca BENZ. É aqui que as formas arredondadas, sinuosas e gordinhas escritas em um vermelho fogo garantem a sensualidade que esta propaganda evoca, justamente pelo estilo gráfico com que são apresentadas. Na terceira parte, por fim, há a caixa de texto com

\footnotetext{
${ }^{14}$ Mais uma vez lembramos que estas análises dizem respeito somente ao que podemos entender da linguagem da publicidade. A recepção por parte dos leitores não faz parte de nossa proposta de trabalho.
} 
o slogan e com as informações sobre o representando no Paraná, Fido Fontana, sobre um fundo bem amarelo que destoa do restante da composição em tons de vermelho. Mais uma vez aqui, podemos perceber o que Baudrillard postulara em relação à publicidade de que as significações sociais dos objetos de consumo são construídas em paralelo aos desejos individuais. $\mathrm{O}$ apelo à sedução, à brincadeira $\mathrm{e}$ ao poder que estas propagandas suscitam auxilia na construção do ideal de uma sociedade moderna.

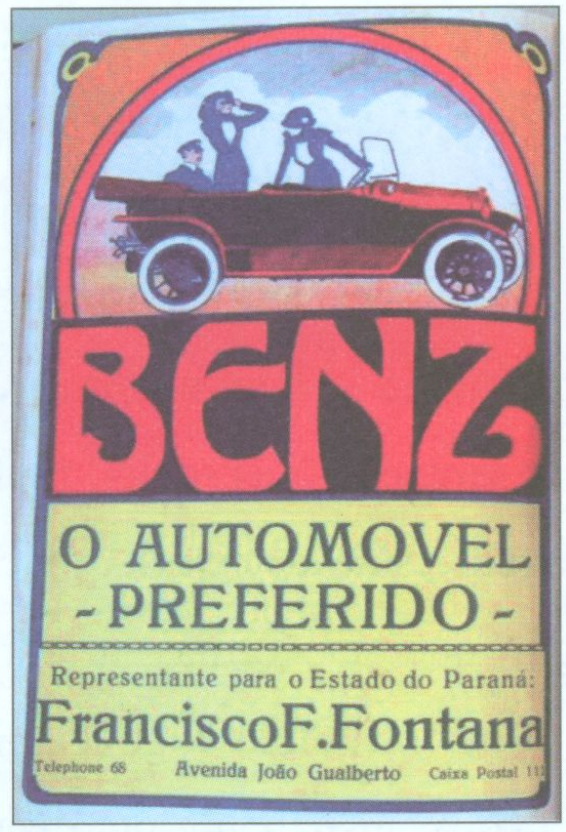

Imagem 5: Quarta capa

anúncio automóveis Benz $A$

Bomba n⿳19 dez/1913 
Contudo, podemos percebemos diferenças nos padrões de representação do automóvel ao longo das cinco propagandas analisadas neste artigo. Do primeiro anúncio, que circulou na revista $A$ Bomba em agosto de 1913, até a última, que foi impressa n'A Bomba de dezembro do mesmo ano, vemos uma diferenciação não só nos aspectos gráficos das imagens, mas também nos valores transmitidos por eles. Voltando novamente ao texto do historiador Artur Freitas, entendemos que a partir das diferentes maneiras formais de representar o automóvel é possível atribuir várias significações sócio-culturais a estas imagens.

Como já apontado anteriormente, nas três primeiras propagandas encontramos o que Martine Joly denominou de construção axial na diagramação da imagem. Ou seja, uma vez que de agosto a outubro as propagandas de automóveis eram uma novidade nos periódicos, ele era o foco central da atenção nas publicidades e tal objetivo era alcançado colocando-o no centro do olhar do leitor. Além disso, os desenhos dos carros representavam a técnica, não só a tecnologia inovadora que o automóvel trazia aos meios de transportes, mas também as novas técnicas da própria imprensa e da representação artística, já que estas conseguiam produzir imagens muito próximas à realidade, ao próprio objeto. Deste modo, vemos a construção pela publicidade do ideal de 
progresso técnico e científico aliado com a obsessão da modernidade em apreender o real em sua forma mais pura e livre de deformações subjetivas.

Já nas propagandas 4 e 5 , temos uma variação da representação do automóvel e, com isso, podemos delimitar outras significações transmitidas por ela. A partir de novembro, ou seja, já no penúltimo mês que $A$ Bomba esteve em circulação, as imagens das propagandas mostram a ideia do automóvel inserido no cotidiano urbano. Esta mudança na composição visual traz consigo uma outra gama de possibilidades interpretativas para o automóvel. Ele passa a ser visto como o símbolo por excelência da era das máquinas, para ser, além disso, objeto de lazer e de convívio entre pessoas que possuíam determinado status social. Ademais, a construção do cenário no qual o automóvel está inserido não possui nenhuma pretensão em reproduzir a realidade, uma vez que brinca com as cores e com as formas do desenho criando, assim, uma outra imagem para a modernidade, qual seja a de descontração e diversão. Este apelo ao lúdico e ao sensual que estas propagandas evocam está intimamente ligado com a visão de mundo cosmopolita da sociedade moderna. Retomemos mais uma vez Baudrillard quando ele diz que a publicidade se alicerça em um discurso de igualdade entre os consumidores, mas que, na prática, ela inspira a uma diferenciação 
social cada vez mais gritante baseada no poder aquisitivo das partes. Se pensarmos que a maioria disparada da população curitibana da época não possuía recursos suficientes para aprender a ler e a escrever, o que dirá de possuírem poder de compra para adquirir um automóvel. As propagandas atendem a um ideal de modernidade que encanta aos olhos e aguça os sentidos de todos, mas que só é atingida por poucos indivíduos.

\section{Considerações Finais}

$\mathrm{O}$ estudo das publicidades veiculadas na revista $A$ Bomba nos permite compreender como o automóvel, signo da modernidade urbana, teve sua entrada simbólica no cenário curitibano do início do século XX através das revistas ilustradas que apareciam cada vez mais na cidade. Outrossim, a figura de Francisco Fido Fontana é aliada à figura do automóvel, uma vez que este era o importador dos carros BENZ e era representante da burguesia ervateira paranaense que tentava se aproximar de todo $o$ jeito às tendências de modernização cosmopolitas. Dessa maneira, as propagandas de automóveis nos permitem refletir sobre pelo menos três processos distintos, porém interligados: 1) a linguagem visual publicitária pela qual um dos símbolos da modernidade era construído; 2) o fenômeno das revistas ilustradas nas metrópoles como agentes que auxiliavam 
na difusão desses ideais e na formação de um gosto e de um juízo estético relacionados aos modelos internacionais e 3) o modo pelo qual Fido Fontana participava neste processo como um dos agentes sociais que possibilitavam a inclusão do modo de vida burguês em Curitiba.

\section{Referências Bibliográficas:}

AUMONT, Jacques. A Imagem. Campinas, São Paulo: Papirus, 1993.

BAUDRILLARD, Jean. A Sociedade de Consumo. Lisboa: Edições $70,1972$.

. "Significação da Publicidade". In LIMA, Luiz Costa (org.).

Teoria da Cultura de Massa. Rio de Janeiro: Editora Saga, 1969.

CHARTIER, Roger. "O mundo como representação" In Estudos Avançados vol. $5 n^{\circ} 11$. São Paulo, janeiro/abril 1991.

CARDOSO, Rafael. "Design, indústria e o consumidor moderno (1850-1930)". In CARDOSO, Rafael. Uma introdução à História do Design. São Paulo: Blucher, 2008.

FREITAS, Artur. "História e Imagem artística: por uma abordagem tríplice". In Estudos Históricos - dossiê História e Imagem. Rio de Janeiro, $n^{0} 34$, julho/dezembro de 2004.

HABERMAS, Jürgen. Mudança Estrutural da Esfera Pública. Rio de Janeiro: Tempo Brasileiro, 2003. 
JOLY, Martine. Introdução à análise da imagem. Campinas, São Paulo: Papirus, 1996.

KAMINSKI, Rosane. "A presença das imagens nas revistas curitibanas entre 1900-1920". In Revista Cientifica/FAP. Curitiba, v.5, jan/jun. 2010.

. O belo efêmero, o gosto brejeiro: imagens da vida fugidia nas revistas curitibanas (1900-1920). Texto apresentado no seminário da Linha de Pesquisa "Intersubjetividade e Pluralidade: reflexão e sentimento na História" da Universidade Federal do Paraná, no dia 05 de maio de 2010.

PADILHA, Márcia. A Cidade como Espetáculo: publicidade e vida urbana na São Paulo dos anos 20. São Paulo: Annablume, 2001.

RAIMES, Jonathan. Design Retrô: 100 anos de design gráfico. São Paulo: Editora Senac SP, 2007.

ORTIZ, Renato. A moderna tradição brasileira: cultura brasileira e indústria cultural. São Paulo: Brasiliense, 1988.

SCHRØDER, Kim \& VESTERGAARD, Torben. A Linguagem da propaganda. São Paulo: Martins Fontes, 1988.

SEVCENKO, Nicolau. "A capital irradiante: técnica, ritmos e ritos do Rio". In SEVCENKO, Nicolau (org.) História da vida privada no Brasil. Vol. 3. São Paulo: Companhia das Letras, 1998. 
Cadernos de Clio, Curitiba, n. ${ }^{\circ} 2,2011$

SORLIN, Pierre. "Enganosas e indispensáveis: as imagens, testemunhas da História". In Estudos Históricos. Rio de Janeiro: $\mathrm{n}^{0} 13,1994$.

TOURRAINE, Alain. Critica da Modernidade. Petrópolis, Rio de Janeiro: Vozes, 1994.

\section{Sites}

http://pt.wikipedia.org/wiki/Desenho_técnico - acesso em $23 / 02 / 2011$. 